\title{
Biographies and Bodies of Pupils of the Amsterdam Maritime Institute, 1792-1943
}

\section{Social and Economic History}

\author{
Björn Quanjer \\ The Radboud Group for Historical Demography and Family History / \\ Radboud Institute for Culture and History, Radboud University Nijmegen, \\ Nijmegen, Netherlands \\ bjorn.quanjer@ru.nl \\ Jan Kok \\ The Radboud Group for Historical Demography and Family History / \\ Radboud Institute for Culture and History, Radboud University Nijmegen, \\ Nijmegen, Netherlands \\ jan.kok@ru.nl
}

\begin{abstract}
In this article, the authors describe and explore the dataset Pupils of the Amsterdam Maritime Institute 1792-1943, which is based on the Comportementboeken of the Amsterdam Maritime Institute. These records contain biographical information and bodily measurements of aspirant sailors between 12 and 20 years of age. The authors have linked the records $(\mathrm{N}=5439)$ to enrolment records and the examinations for the military draft, which provides unique data on historical adolescent growth rates. Apart from anthropometric research, the dataset can be used for different kinds of studies into the background and early careers of Dutch sailors.
\end{abstract}

\section{Keywords}

Maritime Institute - anthropometric history - Amsterdam - sailors - education 
- Related data set "Pupils of the Amsterdam Maritime Institute 1792-1943" with DOI www.doi.org/10.17026/dans-zhg-gmwg in repository "DANs"

\section{Introduction}

The Maritime Institute in Amsterdam (Kweekschool voor de Zeevaart) was founded in 1785 in the aftermath of the fourth Anglo-Dutch war (1780-1784) on the one hand to promote and restore Dutch seafaring to its former glory, and on the other hand to elevate poor boys of the city of Amsterdam. The school existed, with a brief interruption in the Napoleonic years (1811-1814), until 2000. The Institute shows similarities with the charitable Marine Society that was based in London. The records of that school's pupils were used by Floud and Wachter (1982) to study the effect of industrialization on heights and living standards in England. British sailors' heights were recently also studied (Humphries and Leunig, 2009). Therefore the Amsterdam source first and foremost provides an opportunity to conduct a similar study for the Netherlands, since heights of the Amsterdam pupils were recorded as well.

Nevertheless, the richness of the source appeals to many scholarly debates. Within the field of anthropometric history, there are numerous debates that can be addressed. The secular trend in heights that occurred from the middle of the nineteenth century onwards is still not well understood (Hatton \& Bray, 2010). Since conscription heights do not reflect adult stature until the twentieth century (Beekink \& Kok, 2017; Oppers, 1963) it remains unclear if the linear trend is caused by rising adult heights (a vertical shift) or by a compressed growth curve into the teenage years (a horizontal shift). Historical growth curves are rare, yet are crucial to solving this debate (Gao \& Schneider, 2021). The data provided by the Maritime Institute enables us to reconstruct these historical growth curves (Quanjer \& Kok, 2019).

Furthermore the school's requirement $(1807-1830)$ to either be vaccinated against or be recovered from smallpox and the registration thereof makes it possible to contribute to the debate on how particular diseases affected height. Voth and Leunig (1996) found an effect of smallpox on height, but this was attributed to confounding factors by other scholars (Oxley, 2006; Vervaeke \& Devos, 2017).

The biographical information in the records allows for the detection of brothers among the Institute's pupils. This enables us to calculate brother height correlations that will add to the understanding of how important the shared family inheritance was for growth (Alter \& Oris, 2008). Additionally, the recording of parental mortality makes it possible to look at the effects of 
the loss of a father or mother on children's health and life course (RosenbaumFeldbrügge, 2020).

In the social history of seafaring, interest in biographical approaches is growing. Increasingly, sailor's careers in terms of provenance, education and training, family background and financial coping strategies are studied (Van Bochove, 2014; Van Lottum \& Van Zanden, 2014; Vickers, 2005). Although the Amsterdam Maritime Institute focused more and more on training for careers as ship's officers, the information contained in the dataset can offer a good starting point for life course studies on Dutch seafaring men.

In this article, we will first address how the database was constructed and elaborate on its variables. Secondly, we will discuss caveats and potential biases that need to be navigated in the usage of the database. Finally, we will shortly touch upon some of the debates in anthropometric history mentioned above by presenting some results and end with some concluding remarks.

2 Data

- Pupils of the Amsterdam Maritime Institute 1792-1943 deposited at DANS - DOI:www.doi.org/10.17026/dans-zhg-gmwg

- Temporal coverage: $1792-1943$

The main body of the database consists of information from the 'comportementboeken'. These books provide details on the family situation, height and school careers of the students. In the dataset, we have entered most of the biographical information, except for the examination results for the different courses. Data was entered for the period 1792 (the first height recorded) to 1943 (due to privacy regulations). First of all, the dataset contains the name of the research person (RP) together with his place and date of birth. For those born before the introduction of the civil registry, the date of baptism was entered. Furthermore, the names and occupational titles of the parents were registered and their place of residence was included as well. The religion of the RP and his parents was also recorded. Moreover, we have indicated whether one or both of the parents had died. The dataset gives the boy's starting date at the Institute and the date of last observation (generally, after completion of the final exam, but early removal, e.g., for misconduct, or death can also be the reason). The records give information on smallpox vaccination and also state what sum (or free of charge) was paid to start the training and who paid for the training. Last but not least, the height of the students was recorded when they started their training. Until 1820, height was recorded without shoes in 
feet $(28.31 \mathrm{~cm})$ and inches $(2.57 \mathrm{~cm})$, thereafter it was noted according to the metric system. Overall this resulted in a dataset with 5439 students (Quanjer \& Kok, 202Ob).

To apply for a place in the Institute, from 186o onwards, the students' parents had to fill out an application form on one of the application days throughout the country between March and May. Here the candidates were measured for the first time, several months prior to their height examination at the start of their studies in September. In total 2528 of these application forms are collected and can be linked on the basis of a unique ID number. Not all students were admitted in the year they applied, 6.5\% (162) of the applicants' entries were postponed by one year. This enables us to reconstruct growth in a crucial stage of the growth trajectory.

To complete the growth curve, students were linked to their conscription records based on their name and birth date. These conscription records were entered in the context of a crowdsourcing ('Vele Handen') project and are available through WieWasWie. Unfortunately, not all provinces and cohorts were digitized. Therefore we could only retrace 968 conscription records of the pupils in the Maritime Institute. However, only 490 contained a height examination which is not surprising because sailors were often not present at the military draft (Quanjer \& Kok, 2020a). Only during the last years of the First World War, the number of conscription heights was higher due to reduced maritime traffic.

To facilitate usage of the data, occupational titles and places stated in the data were standardized. The occupational titles were standardized according to HISCLASS (Van Leeuwen \& Maas, 2011) building on the HSN standardization scheme (Mandemakers et al., 2018). Places were standardized and linked to their municipality and country. A sizeable group of pupils (374) was born in the Dutch East Indies and we standardized their birthplaces by island. For the Dutch municipalities the Amsterdam code (a diachronic spatial coding system; see Van der Meer \& Boonstra, 2019) was used (municipal borders of 1900) to enable linkage to spatial objects. Finally, based on the first three letters of both the first and last name of both parents (to allow for spelling errors), a family identifier was constructed for full brothers within the data.

Since the data span a period of more than 150 years, compositional changes regarding several variables are visible. Furthermore, regulations for applicants changed and this contributed to compositional effects. Most clearly visible are the age restrictions as shown in Figure 1. The maximum age was raised in 1839 


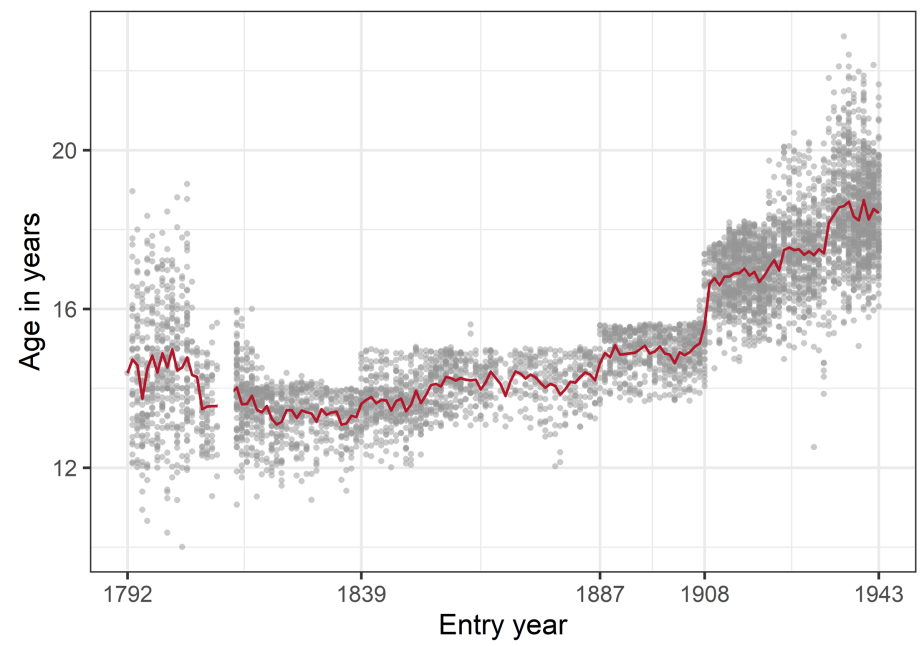

FIGURE 1 Age of students per entry year 1792-1943

QUANJER \& KOK (2O2Ob).

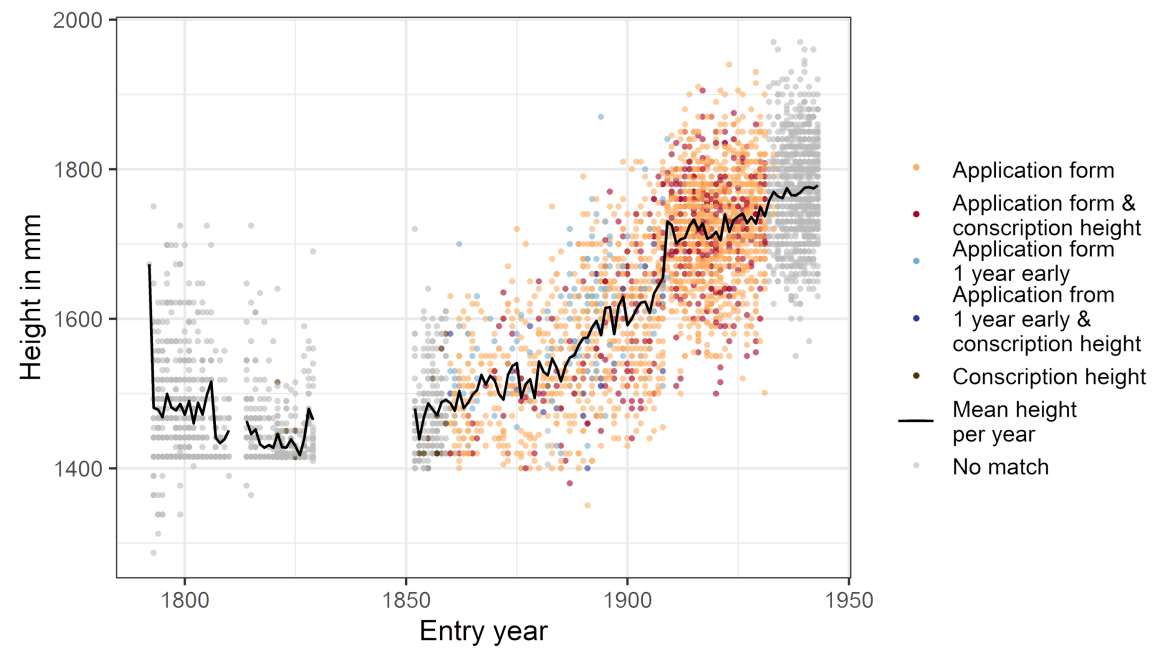

FIGURE 2 Height of students per entry year 1792-1943 including indications if observations are linked to the application form and/or conscription record QUANJER \& KOK (2O2Ob).

and 1887. In 1908, the regulation that students had to have at least three years of high school (HBS) raised the average age even further.

These shifts in age also had an impact on recorded heights. No minimum age was used, since there was a minimum height requirement of $141.5 \mathrm{~cm}$ in place. This is clearly visible in Figure 2, although there are a few exceptions. For the early period, most students started their training when they reached 
the minimum height requirement. This reduced the variance in height, but results in a stronger variation in ages. To compare heights over time, it is recommended to use height-for-age z-score based on a constant reference. In order to facilitate international comparison, in this article, z-scores were calculated using the wHO growth reference for boys per month (World Health Organisation, n.d.). This allows for a comparison of heights across time and age and also enables us to use the early data. For the period 1830-1851 heights were not recorded, possibly because living conditions were so bad that many pupils did not reach the height requirement (De Meere, 1982). After 1851 the majority of heights was rounded to full centimeters. We have no indication for rounding in a particular direction resulting in an upward or downward bias. Actually, the measurements in centimeters are more precise than the inches used in the comparable data of Floud and Wachter (1982). The measurements took place during the first day at the Institute, but we found no indication for a particular order of measurements. Given the fact that during the day the body might shrink by $2-3$ millimeters (Van Wieringen, 1972), we consider this effect to occur randomly within the data.

Throughout the years, the socioeconomic (SES) background of the students changed considerably. In the early years selecting boys from the 'deserving' poor resulted in the fact that at least half of the boys stemmed from families of skilled and unskilled workers, although it needs to be added that during this period one third of the occupations was unknown. Over time the number of registered occupational titles increased. Furthermore, from 1865 onwards the school seems to have been an institute for the middle and upper classes. These changes are visible in Figure 3. Still the development in heights (reflected by height-for-age z-scores) is similar to that of a representative sample of conscripts (Mandemakers, 2018) and follows the nationwide secular trend in heights, rather than just reflecting sEs compositional changes in the Institute. The steeper trajectory can be attributed to a shift in entry ages. Since the wHO growth reference accounts for a modern growth spurt, z-scores of pupils between the age of thirteen and fifteen are downward biased, as the pupils fall behind on the reference growth trajectory more strongly. After the age of fifteen the growth velocity of the reference decreases, whereas the growth velocity of the pupils remains stable or increases due to a later growth spurt, resulting in catching up. Therefore the upward shift in age at entry creates a steeper z-score trajectory in Figure 3. Still it needs to be added that from around the turn of the century, the z-score line is situated above that of the general population. It is very likely that this healthy position is caused by the overrepresentation of middle class and elite 


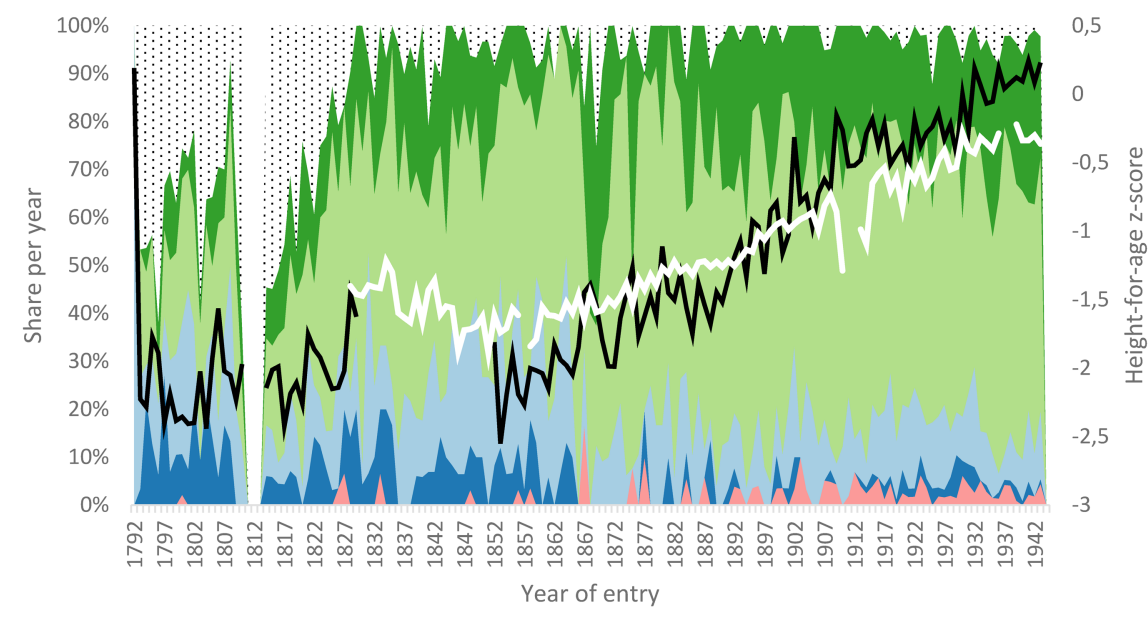

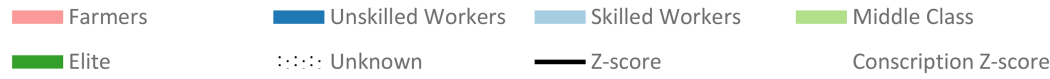

FIGURE 3 Socioeconomic background (HISCLASS 5) determined by parental occupational title and шно referenced height-for-age z-scores per year 1792-1943, including height-for-age z-scores of conscripts with a 5 year time lag MANDEMAKERS (2018), QUANJER \& KOK (2O2Ob).

background. Therefore it is highly recommended to control for the socioeconomic background when analyzing the data.

As the Institute became a place for the (upper) middle classes, the sample is not representative of the Dutch population, although heights seem to have followed a similar secular trend. A second question regarding representativeness is the place of birth. Most students were born in an urban environment (see Figure 4) and 29\% came from Amsterdam itself. Furthermore, there were almost no students from Limburg and the eastern part of Brabant. Throughout the period of observation, especially after opening the new school building in 1880, students started to come from more distant places. A considerable amount of students was born in the Dutch colonies, yet only very seldom to a local mother. Students born in British colonies (mainly India and the Cape colony) joined the Institute as well. Furthermore, the vaccination policy might have affected application from more orthodox religious municipalities. For the period $1807-1830$, this could be tested as it was recorded if the student was vaccinated or already recovered from smallpox. It is to be expected that the share of students who already had smallpox is higher for the orthodox municipalities, which is not the case. Furthermore, we see no difference in the vaccination coverage between Reformed (69\%) and Catholic (65\%) students. Only 


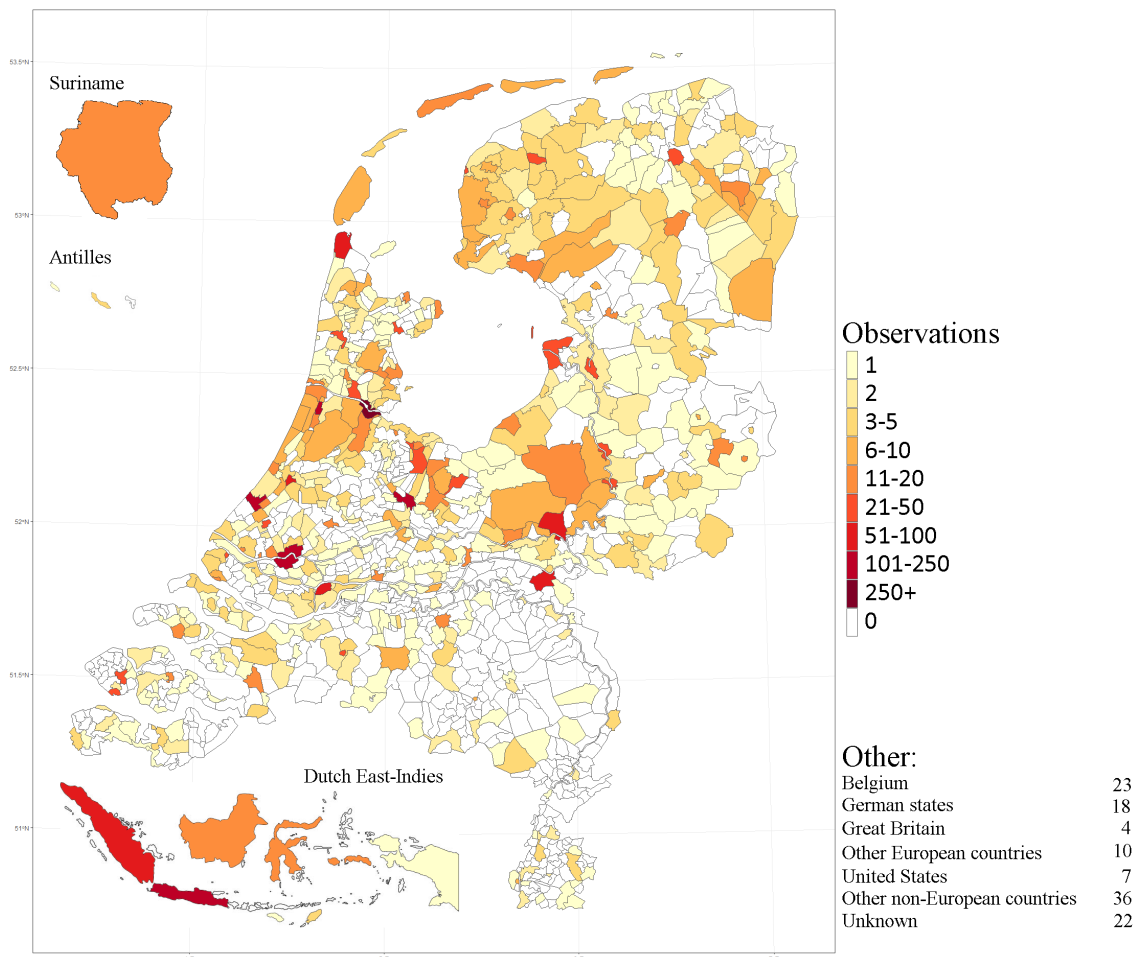

FIGURE 4 Map containing the number of students born in a particular municipality, region or country QUANJER \& KOK (2O2Ob).

Mennonites (Doopsgezind) (5\% of the data) had a higher vaccination rate $(83 \%)$, whereas Lutheran ( $13 \%$ of the data), had a slightly lower vaccination rate $(54 \%)$. Overall, the Institute was primarily protestant, with only $8 \%$ of the students coming from a Catholic background, whereas Jews were completely absent.

\section{$4 \quad$ Results}

Apart from describing the potential of this database, we also present some initial results to show the potential contribution to ongoing scientific debates. First of all, we use the brother linkage (249 brother pairs) in the data to calculate a correlation for their height-for-age z-scores. The overall correlation was o.69. This is higher than found by other studies on nineteenth-century populations (Alter \& Oris, 2008; Thompson et al., 2020). This reflects the higher socioeconomic background of the students; probably their environment shielded 


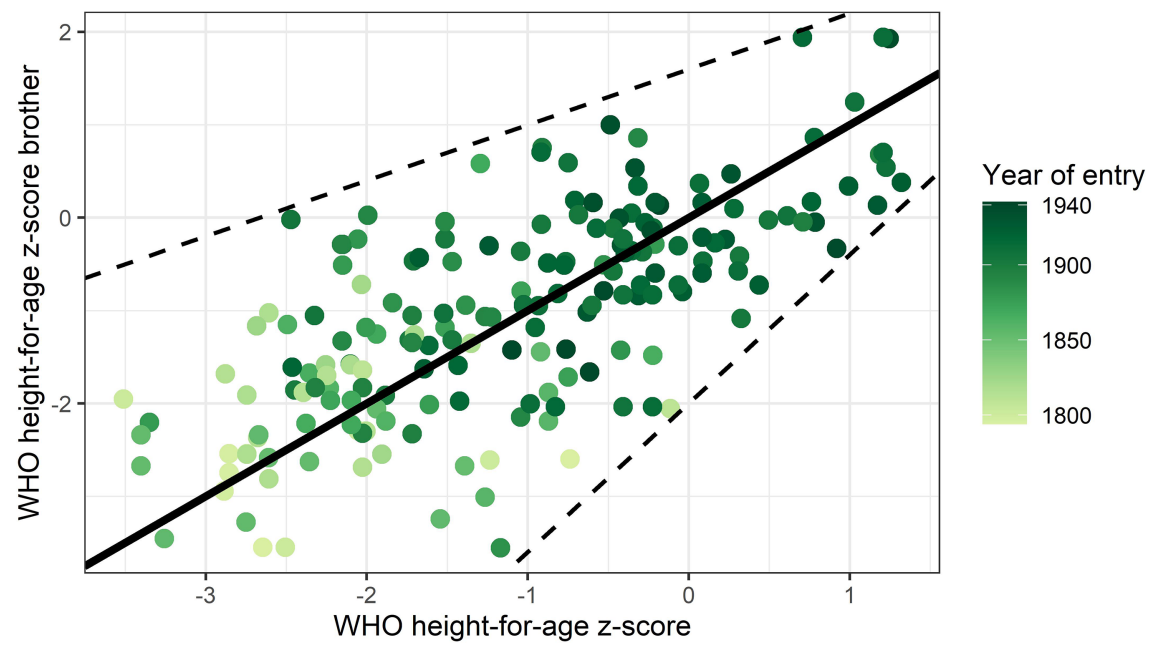

FIGURE 5 Correlation between wHO referenced height-for-age z-scores per year of entry of the first brother

QUANJER \& KOK (2O2Ob).

them against deprivations, thus enabling them to realize a larger share of their genetic potential, resulting in a higher correlation. If we divide the brother pairs into an early group (first brother born before 1875) and a late group (>1875), the correlations are 0.30 and 0.58 respectively. If we divide the groups into young $($ age $<15)$ and old (age > 15) we find 0.5 and 0.7 as correlations. The early correlation of 0.3 is more in line with the literature, and actually captures the same research period (Alter \& Oris, 2008; Thompson et al. 2020). That correlations increase as a result of improved living conditions as was hypothesized by Alter and Oris (2008) is visually captured by Figure 5 . It remains unclear if the higher correlation at an older age is due to the fact that most older observations are also from the end of the research period, or because these research persons had more time to make up for growth lost early in the growth trajectory.

In Figure 6 all data points containing height are visible. Generalized additive mode smoothing was used to draw growth curves for different cohorts. First of all, it is clearly visible that until 1870 the curves are similar and that from 1870 onwards the curves shift upwards. This might be the result of a different socioeconomic composition after 1870, but the fact that the shift in curves continues throughout the rest of the period is an indication that it reflects that of the general population. The year 1870 was also marked as the starting point of the epidemiological transition in the Netherlands (Wolleswinkel-van den Bosch, 1998). Furthermore, between 1870 and 1910 the growth trajectory becomes steeper between age fourteen and sixteen, which is an indication for 


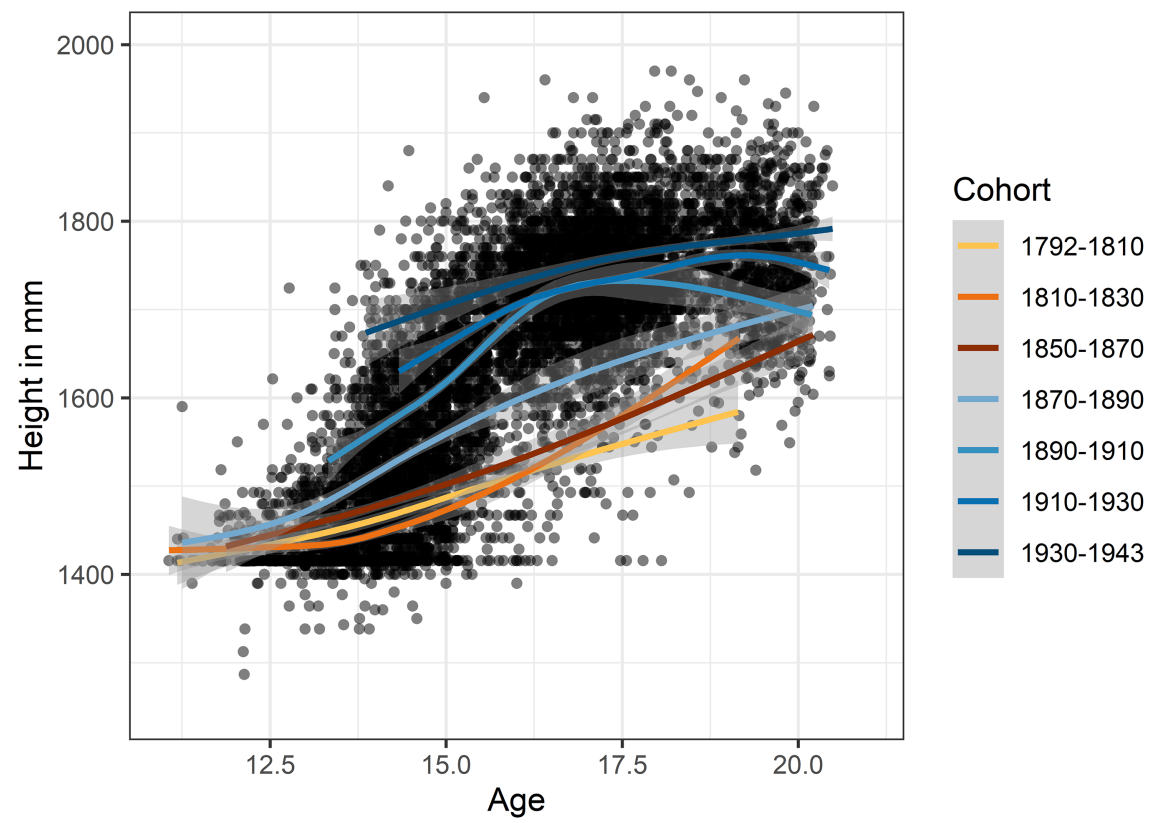

FIGURE 6 Height observations and estimated growth curves per cohort QUANJER \& KOK (2O2Ob).

an earlier growth spurt. It might therefore well be that these middle class boys from urban environments were less affected by their disease environments resulting in a more compressed growth curve.

It needs to be added to the observed biases that the growth curves that include conscription heights are slightly downward biased near the end of the curve. Apparently, only the shorter sailors were available for the conscription examination.

Finally, we tested the effects of parental death and smallpox on height-forage z-scores in two separate linear regression models. After controls (socioeconomic status and period, regression model available upon request), we found that boys who lost their mother were $0.08(\sim 0.6 \mathrm{~cm})$ standard deviations shorter than boys whose mother was still alive. We did not find an effect of paternal mortality, but full orphans were $0.16(\sim 1.2 \mathrm{~cm})$ standard deviations shorter. The maternal mortality effect disappeared when we regressed it on the conscription height. Apparently, resources and care in the Institute were sufficient to catch up on their peers.

In the smallpox model (1807-1830 only, results available upon request) we controlled for the earlier mentioned confounders socioeconomic background and urban birthplace, together with birth year. We found a significant effect on 
z-scores of -0.18 ( 1.3 cm) of boys who suffered from smallpox compared with those who were vaccinated. Since there was a strict minimum height in place, we also found that those who had smallpox were on average 3 months older at the start of their training.

\section{Conclusion}

Overall we are quite confident that this dataset can contribute to debates in historical demography and economic history and, especially, in anthropometric history. Although a sea of biases needs to be navigated, the mostly urban middle and upper-class research population still reflects trends that are also visible in the general population. However, these trends might appear earlier within this research population. The few descriptive findings presented here may already provide an insight into the shift in growth patterns underlying the secular trend in heights, and in the genetic component of growth shown by the brother correlation. Furthermore, the findings related to parental death and smallpox vaccination contribute to the question of how early-life conditions impact stature and growth.

\section{Acknowledgements}

This research is funded by the Netherlands Organisation for Scientific Research (NWO), Giants of the modern world project, 360-53-19o, and the NWo/DANS Klein data project funding 2019-2020.

\section{References}

Alter, G., \& Oris, M. (2008). Effects of inheritance and environment on the heights of brothers in nineteenth-century Belgium. Human Nature, 19(1), 44-55. doi:www.doi. org/10.1007/s12110-008-9029-1.

Beekink, E., \& Kok, J. (2017). Temporary and lasting effects of childhood deprivation on male stature. Late adolescent stature and catch-up growth in Woerden (The Netherlands) in the first half of the nineteenth century. The History of the Family, 22(2-3), 196-213. doi:www.doi.org/10.1080/1081602X.2016.1212722.

De Meere, J. (1982). Economische ontwikkeling en levensstandaard in Nederland gedurende de eerste helft van de negentiende eeuw: aspecten en trends. M. Nijhoff. 
Floud, R., \& Wachter, K. W. (1982). Poverty and physical stature: evidence on the standard of living of London boys 1770-1870. Social Science History, 6(4), 422-452. doi:www.doi.org/10.2307/1170971.

Gao, P., \& Schneider, E. B. (2021). The growth pattern of British children, 1850-1975. The Economic History Review 74(2), 341-371. doi:www.doi.org/10.1111/ehr.13002.

Hatton, T. J., \& Bray, B. E. (2010). Long run trends in the heights of European men, 19th-2oth centuries. Economics \& Human Biology, 8(3), 405-413. doi:www.doi.org/ 10.1016/j.ehb.2010.03.001.

Humphries, J., \& Leunig, T. (2009). Cities, market integration, and going to sea: stunting and the standard of living in early nineteenth-century England and Wales. The Economic History Review, 62(2), 458-478. doi:www.doi.org/10.1111/ j.1468-0289.2008.00458.x.

Mandemakers, K. (2018) HSN dataset Heights and Life Courses, Release 2018_o2 [Dataset].

Mandemakers, K., Mourits, R. J., Muurling, S., Boter, C., Van Dijk, I. K., Maas, I., ... Miles, A. (2018). HSN standardized, HISCO-coded and classified occupational titles, release 2018.01.

Oppers, V. M. (1963). Analyse van de acceleratie van de menselijke lengtegroei door bepaling van het tijdstip van de groeifasen [Doctoral dissertation]. Universiteit van Amsterdam.

Oxley, D. (2006). 'Pitted but not pitied' or, does smallpox make you small? The Economic History Review, 59(3), 617-635. doi:www.doi.org/10.1111/j.1468-0289.2006.00356.x.

Quanjer, B., \& Kok, J. (2019). Tall boys for tall ships? An exploratory study into the heights and growth of teenage boys in the Netherlands 1791-1939. Economic History Society conference, conference paper. https://files.ehs.org.uk/wp-content/ uploads/2020/11/29060844/QuanjerKokFullPaper2019.pdf.

Quanjer, B., \& Kok, J. (2020a). Drafting the Dutch: Selection Biases in Dutch Conscript Records in the Second Half of the Nineteenth Century. Social Science History, 44(3), 501-524. doi:www.doi.org/10.1017/ssh.2020.13.

Quanjer, B., \& Kok, J. (2020b). Pupils of the Amsterdam Maritime Institute 1792-1943 [Dataset]. doi:www.doi.org/10.17026/dans-zhg-gmwg.

Rosenbaum-Feldbrügge, M. T. (2020). Dealing with Demographic Stress in Childhood. Parental Death and the Transition to Adulthood in the Netherlands, 1850-1952 [Doctoral dissertation]. Radboud University.

Thompson, K., Quanjer, B., \& Murkens, M. (2020). Grow fast, die young? The causes and consequences of delayed growth in nineteenth century Maastricht. Social Science Medicine 266, 113430. doi:www.doi.org/10.1016/j.socscimed.2020.113430.

Van Bochove, C.J. (2014). Seafarers and shopkeepers: Credit in eighteenth-century Amsterdam. Eighteenth-Century Studies, 48(1), 67-88. doi:www.doi.org/10.1353/ ecs.2014.0046. 
Van der Meer, A., \& Boonstra, O., (2019). Repertorium van Nederlandse gemeenten vanaf 1812 waaraan toegevoegd de Amsterdamse code: DANs Data Guide 2 (Dataset). doi:www.doi.org/10.17026/dans-xdr-cs36.

Van Leeuwen, M. H., \& Maas, I. (2011). HISCLASs: A historical international social class scheme. Universitaire Pers Leuven.

Van Lottum, J., \& Van Zanden, J. L. (2014). Labour productivity and human capital in the European maritime sector of the eighteenth century. Explorations in Economic History, 53, 83-100. doi:www.doi.org/10.1016/j.eeh.2014.04.001.

Van Wieringen, J. C. (1972). Secular changes of growth [Doctoral dissertation]. Netherlands Institute for Preventive Medicine TNo.

Vervaeke, A., \& Devos, I. (2017). Much Ado about Nothing?: Reconsidering the Smallpox Effect. Height in the Nineteenth-Century Town of Thielt, Belgium. Tijdschrift voor sociale en economische geschiedenis, 14(4), 56-61. doi:www.doi.org/10.18352/tseg.987.

Vickers, D. (2005). Young men and the sea. Yankeer seafarers in the age of sail. Yale University Press.

Voth, H. J., \& Leunig, T. (1996). Did smallpox reduce height? Stature and the standard of living in London, 1770-1873. The Economic History Review, 49(3), 541-56o. https:// onlinelibrary.wiley.com/doi/full/10.1111/j.1468-0289.1996.tboo581.x.

Wolleswinkel-van den Bosch, J. J. (1998). The epidemiological transition in the Netherlands [Doctoral dissertation]. Erasmus University Rotterdam.

World Health Organisation (n.d.) Child growth standards, Length/height-for-age. www. who.int/childgrowth/standards/height_for_age/en/. 